\title{
Acetaminophen in critically ill patients with fever:
}

\author{
Omaima Mahmood ${ }^{(1)}$, Saeed AG Mahmood Ma $^{(2)}$ \\ (1) Qatar University, Doha, Qatar \\ (2) Hamad Medical Corporation, Doha, Qatar
}

\begin{abstract}
:-
Background: Acetaminophen is one of the most treatments used to reduce the temperature in ICU patients. However, it is still unclear whether the use of acetaminophen improves patients' survival and hospital length of stay. This study aims to analyze the main literatures which studied the use of acetaminophen in ICU patients with fever due to infections or other non-infectious insults.

Methods:Severaldatabases including Cochrane library database, Academic Search Complete, and PubMed were searched for studies on acetaminophen in ICU patients. The search was limited to randomized controlled trials, cohort studies, adult human critically ill patients, treatment with acetaminophen in one arm and no treatment (placebo) in the other arm. The outcomes assessed were the ICU and hospital length of stay, mortality rate, ICU-free days and changes in temperature.

Results:Two randomized control trials and one cohort study covering 32,408 patients were included. There wereno differences in ICU and hospital length of stay between the group treated with acetaminophen and placebo. In addition, the mortality rate did not differ between the two groups in patients with fever due to infection; however, a difference was shown in patients with fever due to non-infectious insults. Finally, there was a significant reduction in temperature in acetaminophen group compared to placebo.

Conclusion: The use of acetaminophen for fever in critically ill patients was not associated with better outcome in terms of ICU and hospital length of stay and mortality ratecompared to placebo especially when the fever is due to infections.
\end{abstract}

Key words: Acetaminophen, ICU, infections, paracetamol

\section{INTRODUCTION}

Fever is an important part of human defense system against several types of infections or any other non-infectious insult. It is clinically defined as an elevation in body temperature above $38^{\circ} \mathrm{C}$. Fever is common among critically ill patients in intensive care units (ICU). The incidence of hyperthermia among critically ill conditions ranges from $20 \%$ to $70 \%$ (1). For example, the incidence of fever in severely-brain injured patients during their first week of hospitalization reaches $89 \%$ (2). Although fever is a sign of infection and it may prolong the length of stay in ICU as reported previously (2), there is an argue that the presence of fever plays a key role in provoking the immune system, increasing the clearance of the microbes and it guides the health care providers in identifying the infection, following the infection course and recommending the appropriate therapy (3). Thus, it is still unclear whether managing fever and reducing the host temperature is beneficial to the host. The common practice in most institutions is to administer an antipyretic therapy to manage the fever in critically ill patients (4). Acetaminophen (perfalgan) $1 \mathrm{~g}$ intravenous every 6 hours or as needed is considered the most common antipyretic therapy used in these settings for this purpose. Acetaminophen showed a significant effect in reducing the mean daily peak body temperature and the mean daily average body temperature as reported previously $(4,5)$. However, its effect onother parameters including ICU length of stay, hospital stay and the survival is still controversial. One recent observational study showed that acetaminophen is associated with a reduction in hospital mortality and time to death in ICU patients with fever without an infection(6). However, in a recent randomized controlled trial, acetaminophen did not add any additional benefit comparing to placebo in improving ICU- free days or survival in patients with fever due to infection(5). Therefore, the main objective for this study is to discuss and analyze the main literatures regarding the use of acetaminophen in critically ill patients with fever due to infections or other non-infectious insults.

\section{METHOD AND MATERIALS}

Literature search: Several databases were searched for specific literatures that could meet the inclusion criteria, these databases including Cochrane library database, Academic Search Complete, and PubMed. The main inclusion criteria including randomized controlled trials, prospective or retrospective observational studies, adults human critically ill patients, patients with fever due to infection or other non-infectious insults, and treatment with acetaminophen in one arm versus placebo or no-treatment in the other arm. 
The following terms were used in the searching process including: (Acetaminophen (MeSH Terms]) AND (critical care [MeSH Terms] OR critical illness [MeSH Terms] OR intensive care unit [MeSHTerm]) AND (fever [MeSH Term]). The search was limited to the clinical trials, human subjects and English language. All the selected studies were reviewed for the enrolled patients, the main characteristics, demographics, the follow up period and other important criteria.

The primary outcomes measured were the effect on ICU length of stay and mortality for patients receiving acetaminophen versus placebo. The secondary outcomes were the hospital length of stay, the changes in the temperature and ICU- free days.

Other data extracted were the study design, patients profile, body temperature, overall survival and other hemodynamic parameters.

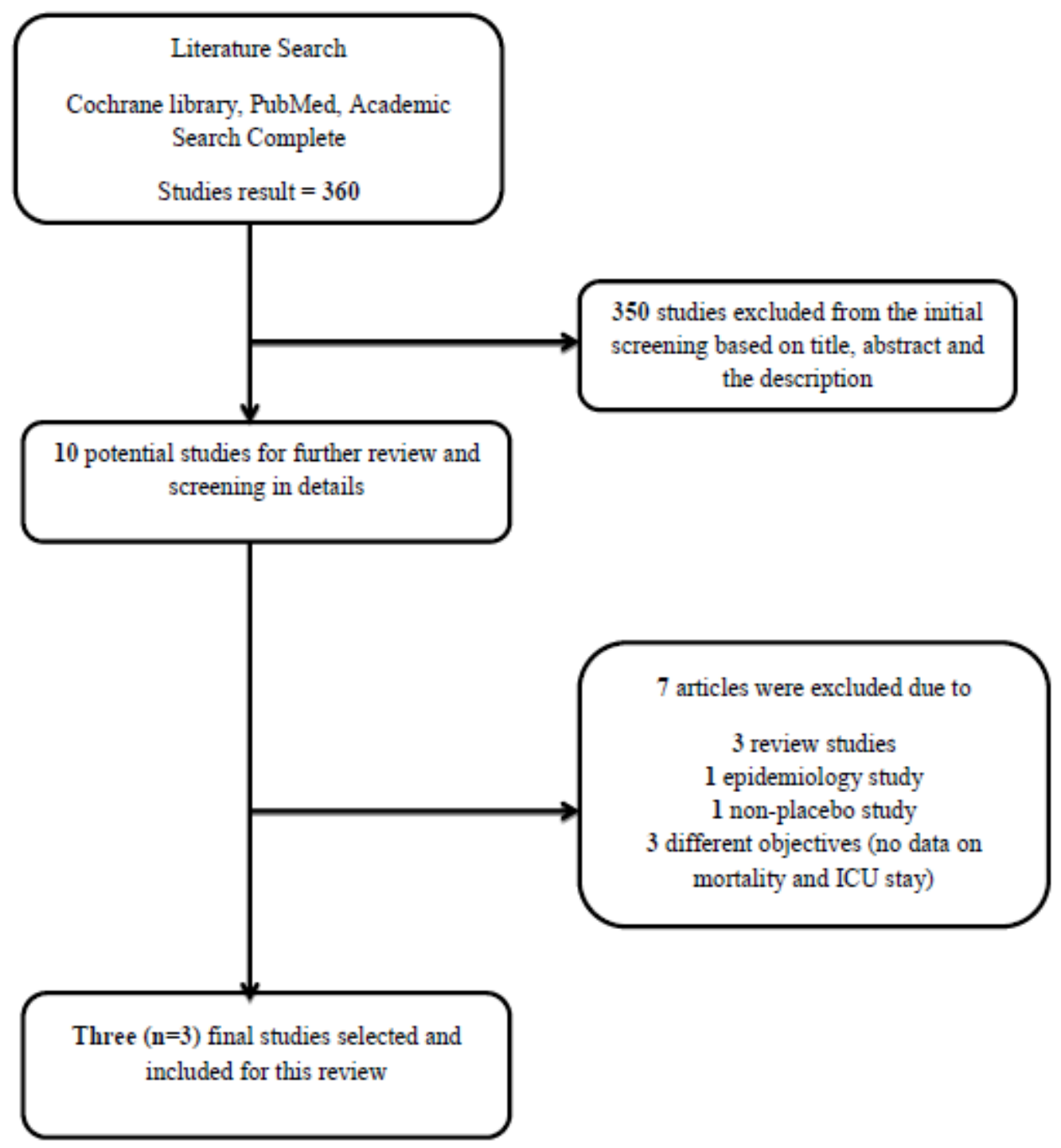

Figure 1.Literature Search details.

\section{RESULTS}

The comprehensive literature search yield around 360 literatures at the beginning, from which 350 were excluded from the first screening due to the title, abstract and description which did not meet the criteria or the objective of this study. Therefore, 10 studies were left for the full text review and detailed screening. Out of these 10 studies, seven $(n=7)$ trials were excluded due to different reasons including: review studies - neither RCT nor observational studies $(n=3)$, comparison between acetaminophen and other medication $(n=1)$, epidemiologicalstudy $(n=1)$ and studies focused on the effect of acetaminophen on oxygen consumption and blood pressure (no data on mortality and ICU length of stay) $(\mathrm{n}=2)$. (Figure 1) 
Acetaminophen in critically ill patients with fever: Review study

\begin{tabular}{|c|c|c|c|c|c|c|}
\hline Studies & Study Design & $\begin{array}{l}\text { Allocation } \\
\text { concealment }\end{array}$ & $\begin{array}{l}\text { Baseline } \\
\text { similarities }\end{array}$ & Randomizatior & $\begin{array}{l}\text { Patients } \\
\text { number (n) }\end{array}$ & $\begin{array}{r}\text { Intention- } \\
\text { to-treat } \\
\text { analysis }\end{array}$ \\
\hline Schulman et al(7) & $\begin{array}{l}\text { Prospective } \\
\text { randomized } \\
\text { clinical trial }\end{array}$ & Sealed envelop & Age,ISS score & $\begin{array}{l}\text { Computer } \\
\text { generated } \\
\text { numbers }\end{array}$ & $\mathrm{N}=82$ & No \\
\hline Young $P$ et al. (8) & $\begin{array}{l}\text { Prospective } \\
\text { blinded, } \\
\text { randomized } \\
\text { controlled trial }\end{array}$ & $\begin{array}{l}\text { Indistinguishable } \\
100-\mathrm{ml} \text { glass } \\
\text { bottle }\end{array}$ & $\begin{array}{l}\text { Age, (APACHE } \\
\text { II) score, severit } \\
\text { of illness }\end{array}$ & Block system & $\mathrm{N}=690$ & Yes \\
\hline Suzuki S et al. (9) & Cohort study & None & $\begin{array}{l}\text { Age, (APACHE } \\
\text { II) score, severit } \\
\text { of illness }\end{array}$ & None & $\mathrm{N}=15,818$ & No \\
\hline
\end{tabular}

Table 1. Quality of the included studies

Randomized controlled trial $(7,8)$ and one prospective observational study (9) were included finally in this review. In all the three studies, the treatment of fever was with acetaminophen in one group and no treatment givento the other placebo group. Other cooling strategies including the cooling blanket were used in these studies when the patient's temperature exceeded specific range. One study evaluated non-surgical patients (8)and the others evaluated both surgical and medical patients $(7,9)$. Two studies included patients with fever and infection at time of diagnosis $(7,9)$, whereas the third study included patients with fever due to other reasons (8). Based on the analysis of these three trials,there is no difference in ICU and hospital length of stay between the group treated with acetaminophen and placebo (Table 2). In addition, there is no difference in the mortality rate between the two groups as reported in one randomized trial (8). However, in the other two studies, there was a difference in mortality rate between the two groups which was in favor of acetaminophen in one study and in the favor of placebo in the other trial $(7,9)$ (Table 2). As expected, patients treated with acetaminophen had lower body temperature compared to placebo at the end of follow up (Table 2).

\begin{tabular}{|c|c|c|c|c|c|c|}
\hline \multirow[t]{2}{*}{ Characteristics } & \multicolumn{2}{|c|}{ Young P et al. (8) } & \multicolumn{2}{|c|}{ Schulman et al. (7) } & \multicolumn{2}{|c|}{ Suzuki S et al. (9) } \\
\hline & Acetaminophen & Placebo & Acetaminophen & Placebo & Acetaminophen & Placebo \\
\hline Patients type & \multicolumn{2}{|c|}{ Surgical and medical } & \multicolumn{2}{|l|}{ Surgical } & \multicolumn{2}{|c|}{ Surgical and medical } \\
\hline Measurement of T & \multicolumn{2}{|l|}{ Axillary } & \multicolumn{2}{|l|}{ Not defined } & \multicolumn{2}{|c|}{$\begin{array}{l}\text { Tympanic, axillary, per rectum, } \\
\text { esophageal and bladder temperature pr }\end{array}$} \\
\hline Patients (n) & 346 & 344 & 44 & 38 & 10,046 & 5,772 \\
\hline Age (years) & $59.1 \pm 16.9$ & $57.9 \pm 17.4$ & $47 \pm 20$ & $47 \pm 20$ & 64 (52 to 73 ) & 62 (49 to 73 ) \\
\hline APACHE II score & $19.1 \pm 6.7$ & $18.7 \pm 7.5$ & $12.8 \pm 7.7$ & $11.4 \pm 6.5$ & $16.5(6.3)$ & $17.7(8.4)$ \\
\hline $\begin{array}{l}\text { Initiation of } \\
\text { acetaminophen }\end{array}$ & $\mathrm{T}>38^{\circ} \mathrm{C}$ & None & $\mathrm{T}>38.5^{\circ} \mathrm{C}$ & None & $\mathrm{T}>38^{\circ} \mathrm{C}$ & None \\
\hline $\begin{array}{l}\text { Additional cooling } \\
\text { mechanism }\end{array}$ & $\begin{array}{l}\text { Physical cooling } \\
\text { If } \mathrm{T}>39.5^{\circ} \mathrm{C}\end{array}$ & $\begin{array}{l}\text { Physical cooling } \\
\text { If } \mathrm{T}>39.5^{\circ} \mathrm{C}\end{array}$ & $\begin{array}{l}\text { Cooling blanket } \\
\text { if } \mathrm{T}>39.5^{\circ} \mathrm{C}\end{array}$ & Only if $\mathrm{T}>40^{\circ} \mathrm{C}$ & \multicolumn{2}{|l|}{ Not defined } \\
\hline Initial T (C) & $38.8 \pm 0.6$ & $38.7 \pm 0.6$ & $38.7 \pm 0.6$ & $38.6 \pm 0.6$ & - & - \\
\hline $\begin{array}{l}\text { T after initiation of } \\
\text { acetaminophen }(C) \text { ) }\end{array}$ & $37.0 \pm 0.6$ & $37.3 \pm 0.6$ & $36.67 \pm 0.69$ & $37.76 \pm 0.59$ & - & - \\
\hline ICU stay, days & 5 & 6 & $22 \pm 30$ & $20 \pm 14$ & - & - \\
\hline Hospital stay (days) & 13.7 & 13.8 & - & - & - & - \\
\hline Mortality (\%) & 48 & 47 & 15.9 & 2.6 & 10 & 20 \\
\hline
\end{tabular}

Table 2. Outcomes of the study included in the review 


\section{DISCUSSION}

Fever may have both beneficial and detrimental effect on the human's body. High temperatureespecially in the life-threatening situations- increases the metabolic rate, consumption of oxygen and affects the general outcomes. However, fever in other situation - especially in relation to infections- may work positively by fighting against the infective organism, decreasing the bacterial growth, and increasing the synthesis of antibodies and cytokines(10). Therefore, using antipyretic is a controversial issue. Acetaminophen is an antipyretic that is used commonly in ICU to treat fever(10). Although it shows a positive effect in reducing fever in ICU patients, there is a concern regarding using it frequently since it can act as a liver toxin by depleting the intracellular glutathione (9). In addition, it may worse the condition in case of infection due to the potential benefit of fever in improving the immune system. Thus, the balance between the beneficial and detrimental effect of acetaminophen may depends on the cause of fever. Therefore, this study is done to provide a review for the literatures discussing this topic and to provide a conclusion and recommendation for the use of acetaminophen to treat fever in ICU patients

From the review of these trials, we found that the use of acetaminophen in ICU patients was not associated with a better outcome in term of decreasing ICU length of stay. However, it was effective in reducing the temperature significantly compared to the other group. This finding was also supported in other studies. A study for Young P et al (11) which included intensive care patients with fever showed that acetaminophen was effective in reducing the temperature in the first 3 days after receiving the medication compared to placebo group. In addition, other study done by LauplandKB(12) showed that the temperature is significantly reduced with the administration of acetaminophen. In addition,it indicated that the range oftemperature reduction is not associated with the reduction of ICU length of stay or mortality which is also supported by our review study.

Regarding the effect of acetaminophen on mortality rate, we found that acetaminophen didn't affect the mortality rate in patients with fever due to infections. This was shown in two studies included in this review $(8,9)$.More interestingly; the mortality rate was shown to be increased in patients with fever and infection who received acetaminophen compared to placebo in other studies. A study done by Lee B et al (10) found that acetaminophen independently increase the 28-day mortality for septic patients ( $\mathrm{p}<0.028)$ but that was not observed in non-septic patients. Another study done by Young $\mathrm{P}$ et al(13) showed that elevated body temperature decrease the risk of mortality in patients with infection, however, it increases the risk of mortality in non-infectious patients. This can be justified by the proposed beneficial effect of fever in improving the host immunity and get rid of the infection. In a study of Kluger et al (14), the elevation of body temperature following an experimental bacterial infection resulted in the improvement ofthe host immunity and survival.

On the other side, patients with fever due to non-infectious insults may be benefited from the administration of acetaminophen. Fever is shown to increase the metabolic demand and consequently the oxygen consumption which worse the condition in case of ICU patients (3). For example, in acute stroke, fever associated with high rate of morbidity and mortality which reached up to $20 \%(15$, 16). Therefore, by the administration of acetaminophen, the metabolic demand decreases and the condition become better.

The limitations of the study include the risk of publication bias which may affect the study's conclusion. In addition, there are only three trials included in this review which may also increase the probability of bias. In addition, one study of this review included small sample size which might affect the power of that study and consequently affect the power of the result. Moreover, the search strategy that is used in this review is simple and not many databases were included in the search which could lead to the loss of other studies. A large systematic review or a meta-analysis is needed to confirm the conclusion of this review.

\section{CONCLUSION}

The results of this review suggest that the use of acetaminophen for fever in critically ill patients was not associated with better outcome in terms of ICU length of stay and mortality rate compared to placebo especially when the fever is due to a suspected or a documented infection. However, it is effective in reducing the temperature significantly. Therefore, acetaminophen should be used in case of high temperature mainly to reduce the fever and for improving patients' comfort and not for the aim of improving the survival.

\section{Conflict of interest:}

The authors declare that there is no conflict of interest

\section{REFERENCES}

[1] G.Y. he Fever and Antipyretic in Critically Illness Evaluation Study (FACE). Japan-Korea Organization for Intensive Care Studies (JAKOICS). 2009

[2] Launey Y, Nesseler N, CousinA,et al. Effect of a fever control protocol-based strategy on ventilatorassociated pneumonia in severely brain-injured patients. Critical Care .2014; 18 (6):689 
[3] Launey Y, Nesseler N, Malledant Y, Seguin P. Clinical review: Fever in septic ICU patients -friend or foe?Launey et al. Critical Care.2011; 15 (3):222

[4] Menkin V. Chemical basis of fever. Science. 1944;100(2598):337-8.

[5] Young P, Saxena M, Bellomo R, Freebairn R, et al. Acetaminophen for Fever in Critically Ill Patients with Suspected Infection.NEngl J Med. 2015;373(23):2215-24

[6] Suzuki S, Eastwood G, Bailey M, Gattas M, et al. Paracetamol therapy and outcome of critically ill patients: a multicenter retrospective observational study. Critical Care.2015; 19:162

[7] Schulman CI, Namias N, Doherty J, etal.The effect of antipyretic therapy upon outcomes in critically ill patients: a randomized, prospective study. Surg Infect (Larchmt). 2005;6(4):369-75.

[8] Young P, Saxena M, Bellomo R, Freebairn R, et al. Acetaminophen for Fever in Critically Ill Patients with Suspected InfectionNEngl J Med 2015; 373:2215-2224

[9] Suzuki S, Eastwood G, Bailey M, et al. Paracetamol therapy and outcome of critically ill patients: a multicenter retrospective observational study. Critical Care 2015, 19:162

[10] Lee BH1, Inui D, Suh GY, et al. Association of body temperature and antipyretic treatments with mortality of critically ill patients with and without sepsis: multi-centered prospective observational study. Crit Care. 2012 Feb 28;16(1):R33

[11] Young P, Saxena M, Eastwood GM, et al. Fever and fever management among intensive care patients with known or suspected infection: a multicentre prospective cohort study. Crit Care Med 2011,13:97102

[12] Laupland KB, Shahpori R, Kirkpatrick AW, et al. Occurrence and outcome of fever in critically ill adults. Crit Care Med 2008, 36:1531-1535.

[13] Young PJ, Saxena M, Beas ley R, et al. Early peak temperature and mortality in critically ill patients with or without infection. Intensive Care Med 2012, 38:437-444

[14] Kluger MJ, Ringler DH, Anver M. Fever and survival. Science. 1975;188(4184):166-8.

[15] Saini M, Saqqur M, Kamruzzaman A, Lees KR, Shuaib A: Effect of hyperthermia on prognosis after acute ischemic stroke. Stroke 2009, 40:3051-3059.

[16] Hajat C, Hajat S, Sharma P: Effects of post stroke pyrexia on stroke outcome:a meta-analysis of studies in patients. Stroke 2000, 31:410-414 